\title{
A PRÁTICA DOCENTE FRENTE AOS DESAFIOS DA APRENDIZAGEM DE ALUNOS COM DEFICIÊNCIA INTELECTUAL, NO PROGRAMA NACIONAL DE ACESSO AO ENSINO TÉCNICO E EMPREGO - PRONATEC ${ }^{1}$
}

\author{
Hyane Assunção de Araújo, Universidade Federal do Piauí ${ }^{2}$ \\ Jeiel Maira Lucena da Silva, Centro Universitário Santo Agostinho ${ }^{3}$
}

\section{RESUMO}

A deficiência intelectual ainda é um grande desafio para a escola regular, visto que, por muito tempo se priorizou o estudo homogeneizado, excluindo aqueles que possuíam dificuldades no aprendizado, decorrentes de alguma deficiência. Além disso, os docentes têm dificuldades em lidar com esse público e nem todas as escolas apresentam projeto pedagógico condizente com as necessidades desses discentes, o que compromete o desenvolvimento de suas potencialidades. Este trabalho científico, realizado através de pesquisa bibliográfica pautada nos ensinamentos de autores como Abrucio (2016), Pimentel (2012), Rodrigues (2008) e Suplino (2009), bem como documentos legais, analisa a problemática da inclusão escolar dos alunos com deficiência intelectual e os desafios dos docentes do Programa Nacional de Acesso ao Ensino Técnico e Emprego - PRONATEC, diante dessa realidade. O estudo aponta as lacunas na formação docente como ponto central dessas dificuldades e apresenta algumas sugestões para a melhoria.

Palavras-chave: Formação Docente. Educação Especial. Inclusão.

\section{ABSTRACT}

The intellectual disability is a big challenge for the common school, because for a long time the society prioritized the homogenize study, exclusion those have some difficulty learning due of some disability. Besides that, the teachers have difficulty in deal with this public and not all schools have pedagogic project befitting with the necessity of this students, compromising the development of yours potentialities. This scientific work, fulfilled through bibliography research based on teachings of Abrucio (2016), Pimentel (2012), Rodrigues (2008), Suplino (2009) and legal documents, analyze the school inclusion problem and the challenge National Program for Access to Technical Education and Employment (PRONATEC) teacher's before this reality. The results show the gaps in the teacher training how the central point these difficulties and introduce some suggests of improvement.

Keywords: Teacher Training. Special Education. Inclusion.

\footnotetext{
${ }^{1}$ Trabalho apresentado no Congresso Brasileiro Ciência e Sociedade (CBCS 2019), promovido pelo Centro Universitário Santo Agostinho, de 03 a 05 de outubro de 2019, em Teresina-PI.

2 Pós-graduada, Engenharia Elétrica. E-mail: hyane@ufpi.edu.br

${ }^{3}$ Pedagoga (UFPI); Mestre em Educação (UFC); Docente UNIFSA. E-mail: jeielucena@yahoo.com.br
} 


\section{conghESSOCIENCIAESOCIEDADE

\section{INTRODUÇÃO}

Ao longo da trajetória histórica, as pessoas com deficiência foram tratadas de diferentes modos, desde o abandono e eliminação (da pré-história à Idade Antiga), ao acolhimento caridoso por conventos/igrejas ou amparo familiar, porém excluso da sociedade (na Idade Média), até a busca pela inclusão (na Idade Contemporânea) (GARGHETTI et. al, 2013). No tocante a deficiência intelectual, esta foi interpretada como comportamento diabólico na Idade Média, problema estritamente médico (loucura) no século XVI, e somente no século XXI passou a ser compreendida de fato, sendo aliada a fatores biológicos e ambientais/sociais (RODRIGUES, 2008).

O direito à educação é uma conquista recente, alcançada apenas no século XXI, quando a Educação Especial tornou-se pauta de discussões internacionais e nacionais. A Política Nacional de Educação Especial na Perspectiva da Educação Inclusiva (BRASIL, 2008) salienta que esta é uma modalidade de ensino que perpassa todos os níveis, etapas e modalidades, abrangendo tanto a Educação Básica quanto a Educação Superior e profissionalizante.

O Programa Nacional de Acesso ao Sistema de Ensino Técnico e Emprego PRONATEC, instituído, pela Lei 12.513/2011, surge então da necessidade do país em ter mão de obra qualificada. Logo, seu objetivo é expandir o ensino profissionalizante para jovens e adultos de baixa renda, povos indígenas, pessoas com deficiência, entre outros.

Os cursos são oferecidos de forma gratuita e contemplam cursos de diferentes áreas como adminsitração, construção civil, redes de computadores, dentre outros. As aulas são ministradas em instituições da Rede Federal de Educação Profissional e Tecnológica, serviços nacionais de aprendizagem e Centros Federais de Educação 


\section{cONwEBESOO CIENCIAESOCIEDADE

tecnológica públicos estaduais, distrital e municipais (SDH/PR e SNPD4, 2013, p. 22 e 23).

Entretanto, receber pessoas com deficiência, em escolas regulares ainda é um grande desafio, visto que as escolas e o corpo de funcionários, principalmente os docentes, em sua maioria ainda não estão aptos a lidarem com as particularidades desse público. Diante disso, o presente trabalho tem por objetivo analisar a problemática da inclusão escolar dos alunos com deficiência intelectual e os desafios dos docentes do PRONATEC diante dessa realidade.

\section{METODOLOGIA DA PESQUISA}

Através de uma abordagem qualitativa e dedutiva, utilizou-se o método observacional, a partir da delimitação do tema até a elaboração do relatório da pesquisa, possibilitando a construção do conhecimento científico, a partir de um problema empírico. Quanto aos procedimentos técnicos, realizou-se uma pesquisa bibliográfica, através da revisão de literatura em obras de autores como Abrucio, Pimentel, Rodrigues e Suplino, bem como documentos legais acerca da problemática.

\section{EDUCAÇÃO ESPECIAL: CONTEXTO HISTÓRICO E BASES LEGAIS}

No Brasil, a problemática acerca das práticas escolares das pessoas com deficiência emergiu no século XIX, através de institutos especializados no atendimento de pessoas com deficiência visual (Imperial Instituto dos Meninos Cegos, 1854) e auditiva (Imperial Instituto dos Surdos Mudos, 1857), que funcionam até hoje (BRASIL, 2015).

Em 1926, surgiu o Instituto Pestalozzi, que atende pessoas com deficiência mental e em 1945, na mesma instituição, foi criado o primeiro atendimento

\footnotetext{
${ }^{4}$ Secretaria de Direitos Humanos da Presidência da República (SDH/PR) / Secretaria Nacional de Promoção dos Direitos da Pessoa com Deficiência (SNPD).
} 


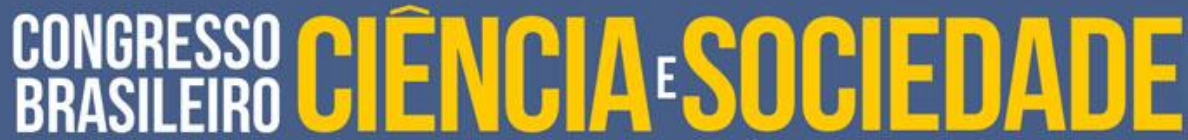

educacional especializado a pessoas com superdotação. Em 1954, foi fundada a primeira Associação de Pais e Amigos dos Excepcionais (APAE) (BRASIL, 2015). Os movimentos pestalozziano e apaeano foram fundamentais para impulsionar ações voltadas às pessoas com deficiência intelectual. Desse modo, os trabalhos realizados por essas organizações aliavam perspectivas educacionais e saúde.

Em 1988, a Constituição Federal tornou a educação um direito básico de todo cidadão brasileiro, incluindo as pessoas com deficiência. Outras leis e portarias foram estabelecidas a fim de estruturar o sistema de ensino da Educação Especial, como a Lei de Diretrizes e Bases da Educação Nacional (1996) e a Resolução 02 do Conselho Nacional de Educação (2001), porém, na prática, o conceito de escola inclusiva ainda não é aplicado em sua totalidade, pois o ensino regular torna-se uma opção e não uma obrigatoriedade, assim as pessoas com deficiência continuam à margem do sistema educacional (BRASIL, 2015).

No âmbito internacional, destaca-se a Declaração de Salamanca, publicada em 1994, que busca a igualdade de direitos e é um dos primeiros documentos que defende a matrícula de alunos com deficiências em escolas de ensino regular, servindo de base para a construção da escola inclusiva.

Em 2006, o documento da Convenção sobre os Direitos das Pessoas com Deficiência, outorgada pela ONU, introduz, no ser artigo 1으, um novo conceito de pessoas com deficiência, citado por Rodrigues (2008, p.23):

\footnotetext{
Aquelas que têm impedimentos de longo prazo de natureza física, mental intelectual ou sensorial, os quais, em interação com diversas barreiras, podem obstruir sua participação plena e efetiva na sociedade em igualdade de condições com as demais pessoas.
}

O Brasil ratifica essa Convenção através do Decreto Legislativo 186/2008 e do Decreto Executivo 6949/2009. Modificações no cenário educacional continuam a ocorrer ao longo dos anos, no entanto, Rodrigues $(2008$, p.20) ressalta que "ainda que haja legislação que preconiza o atendimento às pessoas com deficiência, o mesmo não chega a $40 \%$ da população que necessita dos serviços especializados". O autor ainda 


\section{CONGRESSO CIENCIAESOCIEDADE
BRASILERTO \\ Inovação, Diversidladle e Sustentahilitadide}

observa que pessoas com deficiência intelectual são as que mais necessitam de apoio educacional devido esse tipo de deficiência ser o mais frequente na população.

\section{DEFICIÊNCIA INTELECTUAL: CONCEITUAÇÃO E CONCEPÇÕES}

A priori, é válido fazer a distinção entre "doença mental" e "deficiência mental ou intelectual". Conforme o Secretariado Nacional para a Reabilitação e Integração das Pessoas com Deficiência de Lisboa (2005), a doença mental refere-se a perturbações psiquiátricas que afetam o funcionamento e o comportamento emocional, social e intelectual, possuem diferentes níveis de gravidade e podem manifestar-se de forma aguda, crônica ou intermitente. Já a deficiência mental está ligada a fatores de desenvolvimento (intelectual e comportamental) causados por infecções biológicas e afecções orgânicas e fatores socioculturais devido a causas sociais e psicológicas complexas. Portanto, não é por si própria uma doença.

Outra distinção de especial relevância refere-se à "deficiência de desenvolvimento" e a "deficiência intelectual" apresentada no 11으 manual Deficiência Intelectual: Definição, Classificação e Níveis de Suporte, em 2011, na qual a primeira é definida como uma deficiência grave e crônica que pode ser cognitiva, física ou ambas, enquanto que a segunda refere-se a deficiências que estão amplamente relacionadas ao pensamento processual (ALMEIDA, 2012). Logo, a deficiência intelectual pode ser compreendida como um subgrupo pertencente à deficiência de desenvolvimento.

Dados do Instituto Brasileiro de Geografia e Estatística (2015) revelam que a proporção de pessoas com deficiência no país é de $6,7 \%$, sendo prevalência de $0,8 \%$ de deficiência intelectual. Mais de 50\% possui grau intenso ou muito intenso de limitação.

\section{DESAFIOS DOS DOCENTES DO PRONATEC DIANTE DA DEFICIÊNCIA INTELECTUAL DOS DISCENTES}




\section{CONGERESO CIENCIAESOCIEDADE
BRASILERORO

A Educação Inclusiva, embora resguardada por leis e diretrizes, ainda enfrenta sérios problemas. As escolas ainda não estão preparadas para receber alunos com deficiências, principalmente a rede pública de ensino. Somado a isso, Rabêllo (2009, p. 348) comenta que "a formação inicial do professor nos moldes atuais geralmente não considera as necessidades emergentes do sistema de ensino".

Com referência as escolas pode-se destacar vários questionamentos acerca do currículo escolar, apoio pedagógico e integração escola-família. Batista; Mantoan (2006) salientam que de modo a enquadrar as escolas ao padrão inclusivo, foram tomadas algumas medidas paliativas como adaptação do currículo escolar, bem como adaptação das atividades e avaliações. No entanto, essa solução imediatista acaba por reforçar o caráter substitutivo da Educação Especial, dificultando o processo de inclusão.

Quanto ao apoio pedagógico, destaca-se o Atendimento Educacional Especializado e demais suportes aos portadores de deficiência intelectual. Todavia, nem todas as escolas que oferecem o PRONATEC usufruem dessa ajuda. Somado a isso, destaca-se a quantidade de alunos na sala de aula, fator que inviabiliza o atendimento individualizado para as pessoas portadoras de deficiência intelectual. Além disso, a realidade social dos alunos é muito diversa, nem todas as famílias aceitam que o problema de aprendizado do filho possa ser decorrente de uma deficiência e outras, mesmo conhecendo o diagnóstico, não possuem informações sobre os tratamentos adequados que favorecem o desenvolvimento do indivíduo.

Outra questão a ser discutida é a qualidade dos cursos oferecidos pelo programa. De modo geral, são tecnológicos e específicos, por isso os docentes de várias disciplinas têm formação em bacharel e não em licencatura. Por exemplo, no curso de Instalador e Reparador de Redes de Computadores há matérias ministradas por Engenheiros Eletricistas, técnicos ou Engenheiros de Segurança do Trabalho e Bacharéis em Ciência da Computação. Nesse sentido, salienta-se que os cursos de bacharelado não preparam profissionais para o exercício da docência. Acerca disso, 


\section{CONGRESSO CIENCIAESOCIEDADE
BRASILERTO

Barros; Dias (2016, p. 45) mencionam que "além de competência técnica, dos conhecimentos específicos e da experiência na profissão, a prática de ensino na educação requer o desenvolvimento de saberes pedagógicos [...]"

Nesse contexto, percebe-se que as lacunas na formação do professor, relacionadas ao aspecto didático-pedagógico, aumentam seus desafios em sala de aula, pois além do despreparo didático e falta de conhecimentos de práticas pedagógicas, existe a falta de aptidão em lidar com os mais diversos públicos. Segundo Franzoi; Costa (2013, p. 13) “o PRONATEC ignora a formação dos professores para atuar com este público, que muitas vezes, não têm escolaridade suficiente para os cursos propostos". Percebe-se que o alunado muitas vezes têm dificuldades em acompanhar o curso por não ter conhecimentos básicos que lhe permitam a compreensão dos conteúdos, deixando-os desestimulados e em certos casos, sendo causa da evasão escolar.

No que se refere aos portadores de deficiência intelectual, como Suplino (2009, p. 60) ressalta "Ao longo de sua vida escolar não foram poucas as situações nas quais as tentativas de aprender resultaram em frustrações. Em muito casos, os alunos e suas famílias escutaram que eles jamais iriam aprender". Assim, além das dificuldades da própria deficiência o aluno chega à escola com baixa autoestima e acreditando que não tem potencial. Isto se torna um desafio a mais para o professor que tem lacunas em sua formação pedagógica, pois precisa desenvolver estratégias metodológicas adequadas às necessidades de aprendizagem, para despertar no aluno o desejo de aprender e facilitar o desenvolvimento das competências e habilidades inerentes aos conteúdos e objetivos propostos.

Mais uma vez, esse desafio recai sobre a formação do docente. Muitos cursos e programas do governo oferecem cursos de Libras e Braile, bem como materiais didáticos adaptados, contudo, poucos são os esforços e avanços no que se refere à deficiência intelectual. É difícil encontrar cursos que busquem respaldo na Pedagogia e Psicopedagogia, no sentido de auxiliar o professor a distinguir o aluno com 


\section{cONwEBESOO CIENCIAESOCIEDADE

dificuldades comuns de aprendizagem, daquele que de fato apresente algum tipo de deficiência intelectual.

Abrucio (2016) ainda acrescenta, como um dos principais problemas na formação docente, o perfil do aluno que poderá ser futuramente professor e atratividade/motivação da carreira docente. Em concordância a esta ideia, Suplino (2009) diz que para trabalhar com esse público tão particular (portadores de deficiência mental) é necessário não se ater às barreiras, mas encarar como oportunidade. É uma doação constante. É receber como maior reconhecimento o progresso do aluno. Por isso, retomando Abrucio (2016), nota-se como é importante o perfil desse candidato a docente, pois deve ser alguém empenhado e que busque se aperfeiçoar por meio da formação continuada.

No entanto, essa busca muitas vezes é difícil e parte de uma vontade particular. Desse modo, apesar da educação profissional ter o dever de desenvolver as competências e habilidades individuais, bem como assegurar a evolução cognitiva dos alunos, como menciona Nascimento (2009), a falta de apoio técnico, de apoio familiar e o despreparo do professor comprometem muito o desenvolvimento da pessoa com deficiência intelectual.

\section{ESTRATÉGIAS PARA A MELHORIA DA PRÁTICA DOCENTE}

Muitos são os desafios para que se tenha uma escola inclusiva efetiva, nesse sentido, a melhoria da prática docente é o fator central para obter essa mudança. Portanto, é preciso uma reformulação na estrutura curricular dos cursos de licenciatura e bacharelado, incluindo disciplinas acerca da educação especial para que o docente seja capacitado para lidar com as múltiplas deficiências existentes. Além disso, torna-se necessário que esse docente seja assessorado em sua prática de sala de aula, a partir do planejamento, desenvolvimento e avaliação da ação docente, pois se entende que somente com a prática se consegue desenvolver competências e habilidades, especialmente se tratando de um público com tantas peculiaridades. 


\section{CONGRESSO CIENCIAESOCIEDADE
BRASILERTO

Como Pimentel (2012, p. 142) afirma “é necessário que o professor possua um conjunto de saberes que envolvem as epistemologias que fundamentam o ato de aprender, além de habilidades e competências sobre mediação pedagógica no processo de ensinar". Isso ajuda no reconhecimento de deficiências, bem como norteia o docente em como explorar as potencialidades dos alunos. Vale ressaltar que esses conhecimentos não excluem a importância dos profissionais do Atendimento Educacional Especializado, bem como os profissionais de saúde.

Outro aspecto importante é a necessidade de rever os Projetos Políticos Pedagógicos das escolas. Como Batista; Mantoan (2006, p. 13) ressaltam que "ao invés de adaptar e individualizar/diferenciar o ensino para alguns, a escola comum precisa recriar suas práticas, [...] sempre reconhecendo e valorizando as diferenças".

Nesse caso, "o professor, na perspectiva da educação inclusiva, não é aquele que ministra um "ensino diversificado" para alguns, mas aquele que prepara atividades diversas para seus alunos (com e sem deficiência mental) ao trabalhar um mesmo conteúdo curricular" (BATISTA e MANTOAN, 2006, p. 13). Nessa perspectiva, a avaliação não deve ser pontual, mas sim contínua. O professor precisa desenvolver atividades e acompanhar a evolução/progresso do estudante e não atribuir notas com base apenas em provas tradicionais.

Desse modo Suplino (2009) apresenta o currículo funcional que é pautado na escolha de conteúdos estudados, e que tenham utilidade para a vida no momento atual ou em médio prazo, favorecendo o convívio e proporcionando certo grau de independência ao aluno. No entanto, a implantação dessa metodologia deve integrar toda a equipe pedagógica da escola e incluir a família para atingir melhores resultados.

A escola deve proporcionar liberdade ao professor na escolha da metodologia aplicada em sala de aula e meios de avaliação que serão adotados, e oferecer suporte institucional, tanto pedagógico quanto instrumental (materiais didáticos e recursos de multimídia especial) e infraestrutura para que ele possa desenvolver melhor suas práticas docentes. 


\section{CONGERESSOCIENCIAESOCIEDADE

\section{CONSIDERAÇÕES FINAIS}

Discutiu-se a problemática da inclusão escolar dos alunos com deficiência intelectual e os desafios dos docentes do PRONATEC frente a essa realidade. Diante do exposto, percebeu-se que a grande lacuna a ser suprida refere-se a deficiência didático-pedagógica dos docentes, pois muitos são bacharéis e não possuem experiência de trabalho com esse alunado. A superação está, portanto, centrada na capacitação e formação continuada.

As melhorias nas práticas docentes juntamente com apoio institucional e do governo impulsionam a mudança social. A nova mentalidade que daí surgirá, haverá de manifestar-se, com maior vigor, no seio de uma sociedade mais integrada e imbuída de um forte sentimento de empatia e solidariedade humana, alcançando assim, um meio social verdadeiramente inclusivo.

Para trabalhos futuros, sugere-se aprofundar essa pesquisa para torná-la um estudo de caso por meio de pesquisa de campo, de modo a verificar e analisar as percepções dos professores e dos alunos, quanto aos entraves existentes e as possibilidades de mudança rumo a uma melhor qualidade no processo ensinoaprendizagem.

\section{REFERÊNCIAS}

ABRUCIO, F. L. Formação de Professores no Brasil: Diagnóstico, agenda de políticas e estratégias para a mudança. São Paulo: Moderna, 2016. Disponível em: < http://www.moderna.com.br/lumis /portal/file/fileDownload.jsp?fileld=8A808A8254C1CF7A0154C4400B00099C $>$ Acesso em 3 set.2019.

ALMEIDA, M.A. O Caminhar da Deficiência Intelectual e Classificação pelo Sistema de Suporte/Apoio. In: .(Org). Secretaria da Educação. Núcleo de Apoio

Pedagógico Especializado - CAPE. Deficiência intelectual: realidade e ação. São Paulo: SE, 2012. Disponível em: <http://cape.edunet.sp.gov.br/textos/textos/Livro\%20DI.pdf> Acesso em 3 set.2019.

BATISTA, C. A. M.., MANTOAN M. T. E. Educação inclusiva: atendimento educacional 


\section{CONBGESSOCOENCIASSOCIEDADE}

especializado para a deficiência mental. 2a ed. Brasília : MEC, SEESP, 2006.

Disponível em: <http://portal.mec.gov.br/seesp/arquivos/pdf/defmental.pdf> Acesso em 3 set.2019.

BARROS, C. de M.P., DIAS, A.M.L. A formação pedagógica de docentes bacharéis na educação superior: construindo o Estado da Questão. Revista Educação em Questão, Natal, v. 54, n. 40, p. 42-74, jan./abr. 2016. Disponível em:

<file://C:/Users/Windows/Desktop/9848-Texto\%20do\%20artigo-26920-1-10-

20160725.pdf> Acesso em 2 set.2019

BRASIL. Orientações para Implementação da política de educação especial na

Perspectiva da educação inclusiva. 2015. Disponível em:

$<$ http://portal.mec.gov.br/index.php?option=com

_docman\&view=download\&alias=17237-secadi-documento-subsidiario-

2015\&ltemid=30192> Acesso em 1 nov. 2018.

Política Nacional de Educação Especial na Perspectiva da Educação

Inclusiva. Brasília: MEC/SECADI, 2008. Disponível em:

$<$ http://portal.mec.gov.br/index.php?option=

com_docman\&view=download\&alias=16690-politica-nacional-de-educacao-especialna-perspectiva-da-educacao-inclusiva-05122014\&Itemid=30192> Acesso em 1 nov.2018.

INSTITUTO BRASILEIRA DE GEOGRAFIA E ESTATÍSTICA. Pesquisa nacional de saúde 2013: ciclos de vida: Brasil e grandes regiões. Rio de Janeiro: IBGE; 2015. Disponível em: < https://biblioteca.ibge.gov.br/visualizacao/livros/liv94522.pdf> Acesso em 16 out.2019

FRANZOI, N. L. ; SILVA, C. O. B. ; COSTA, R. C. D. . PROEJA E PRONATEC: CICLO DE POLÍTICAS, POLÍTICAS RECICLADAS. Políticas Educativas, v. v. 6, p. 84-100, 2013. Disponível em: < http://seer.ufrgs.br/index.php/Poled/article/viewFile/45658/28838> Acesso em 5 set. 2019 .

GARGHETTI, F. C., MEDEIROS, J. G., NUERNBERG, A. H. Breve história da deficiência intelectual. Revista Electrónica de Investigación y Docencia (REID), Espanha, v. 10, p.101-116, 2013. Disponível em:

<http://www.revistareid.net/revista/n10/REID10art6.pdf> Acesso em 6 set.2019.

NASCIMENTO, E. S. A EDUCAÇÃO PROFISSIONAL: interfaces com a educação especial. In: DÍAZ, F., BORDAS,M., GALVÃO, N., MIRANDA, T. (Org). Educação inclusiva, deficiência e contexto social: questões contemporâneas. Salvador: EDUFBA, 2009. Disponível em: 


\section{cONGQBESSO CIENCIAESOCIEDADE

<https://repositorio.ufba.br/ri/bitstream/ufba/170/1/Educacao\%20Inclusiva.pdf> Acesso em 3 set. 2018.

PIMENTEL, S. C. Formação de professores para a inclusão - Saberes necessários e percursos formativos. In: MIRANDA, T.G.; FILHO, T. A.G. (Org). $\mathbf{O}$ professor e a educação inclusiva: formação, práticas e lugares. Salvador: EDUFBA, 2012. Dispoível em: <http://www.galvaofilho.net/noticias/baixar_livro.htm> Acesso em 19 set.2018.

RABÊLLO, R.S. A Formação Continuada do Professor de Arte na Perspectiva de uma Educação Inclusiva. In: DÍAZ, F., BORDAS,M., GALVÃO, N., MIRANDA, T. (Org). Educação inclusiva, deficiência e contexto social: questões contemporâneas Salvador: EDUFBA, 2009. Disponível em: <https://repositorio.ufba.br/ri/bitstream/ufba/170/1/Educacao\%20Inclusiva.pdf> Acesso em 3 set.2018.

RODRIGUES, O. M. P. R. Educação especial: história, etiologia, conceitos e legislação vigente. In: CAPELLINI, V. L. M. F. (org.). Práticas em educação especial e inclusiva na área da deficiência mental. Bauru : MEC/FC/SEE, 2008. Disponível em: <http://www2.fc.unesp.br/educacaoespec ial/material/Livro2.pdf> Acesso em 5 set. 2018

Secretaria de Direitos Humanos da Presidência da República (SDH/PR). Secretaria Nacional de Promoção dos Direitos da Pessoa com Deficiência (SNPD). VIVER SEM LIMITE - Plano, Nacional dos Direitos da Pessoa com Deficiência- SDH-PR/SNPD, 2013. Disponível em:

<http://www.pessoacomdeficiencia.gov.br/app/sites/default/files/arquivos/\%5Bfield_ generico_imagens-filefield-description\%5D_0.pdf> Acesso em 13 set.2018.

Secretariado Nacional para a Reabilitação e Integração das Pessoas com Deficiência. DIFERENÇAS SIGNIFICATIVAS ENTRE DEFICIÊNCIA E DOENÇA MENTAL. Lisboa, 2005. Disponível em:

$<$ http://www.inr.pt/download.php?filename=54++Diferen\%E7as+significativas+entre+ defici\%EAncia+mental+e+doen\%E7a+mental\&file=\%2Fuploads\%2Fdocs\%2FEdicoes\%2 FFolhetos\%2FFolheto054.pdf.> Acesso em 5 set.2019.

SUPLINO, M. Currículo Funcional Natural: Guia prático para a educação na área do autismo e deficiência mental. 3a ed. (Revisada) - Rio de Janeiro: Secretaria Especial dos Direitos Humanos, Coordenadoria Nacional para a Integração da Pessoa Portadora de Deficiência; Rio de Janeiro: CASB-RJ, 2009. 